\title{
Vitrectomy in double-perforation gunshot injury
}

This article was published in the following Dove Press journal:

Clinical Ophthalmology

6 November 2013

Number of times this article has been viewed

\section{Ahmed Abd El Alim Mohamed \\ Ophthalmology department, Ain Shams University, Cairo, Egypt}

Correspondence: Ahmed Abd El Alim Mohamed

Ain Shams University, Khalifa

El-Maamon Street, Abbziya

Square, Cairo II566, Egypt

Email ahmed.abdelalim540@yahoo.com
Objective: This study sought to evaluate the result of pars plana vitrectomy in patients with gunshot wounds involving double perforation.

Methods: This was a retrospective, noncomparative, interventional case series.

Results: Eighteen patients (18 eyes) with double-perforation gunshot injuries were treated from February 2010 to March 2012. The group included 16 men (88\%) and two women (11\%); the mean age was 24 (15-33) years. In each case, vitrectomy was scheduled 1-6 weeks after repair of the entrance site. Associated retinal detachments were observed in two eyes (11\%), retinal incarceration was observed surrounding the exit site in three eyes (16\%), and retention of an intraocular foreign body was observed in two cases. After a follow-up period of $8 \pm 2$ months, two eyes $(11 \%)$ had achieved visual acuity (VA) of 0.5 , nine eyes (50\%) had achieved VA between 0.5 and 0.1 , and seven eyes (38\%) had achieved VA between 0.1 and hand movement. The main reasons for functional failure (VA 0.1 to hand movement) were macular dragging (due to fibrosis at the exit site near the macula) in seven cases (38\%), submacular hemorrhage in four cases (22\%), and epimacular fibrosis in five cases (27\%). All cases developed postoperative exotropia. One case (5\%) developed postoperative hemorrhage. No cases exhibited signs of postoperative redetachment.

Conclusion: The outcome of pars plana vitrectomy in cases with double perforations is variable. Factors including the surgeon's skill level, the time to surgery, and the efficacy of the intraocular tamponade affect the postoperative outcome.

Keywords: pars plana vitrectomy, gunshot injury, double perforation

\section{Introduction}

The revolution that began on January 25, 2011 in Egypt has resulted in an increased number of gunshot wounds. The associated ocular injuries include retained intraocular foreign bodies (IOFBs) and double-perforation injuries. The standard approach to treating double-perforation injuries is primary repair to restore the structural integrity of the globe at the earliest opportunity. ${ }^{1}$ If an intraocular or intraorbital foreign body exists, the retina should be examined carefully. If there is any damage, the physician must determine whether surgical intervention will be necessary. The visual prognosis in these cases depends on the degree of injury, and has improved since the advancement and refinement of vitreous microsurgical techniques. ${ }^{2-12}$ The present study aimed to evaluate the visual outcome in patients who had undergone pars plana vitrectomy after double-perforation gunshot injury.

\section{Materials and methods}

This retrospective, noncomparative, interventional case series included 18 patients (18 eyes) with double-perforation gunshot injuries treated by vitrectomy. Each was 
operated on using an injection of silicone oil 5000, from February 2010 to March 2012.

The exclusion criteria were corneal entry, central exit (optic disk or foveal) and/or visual acuity (VA) of less than light perception. All patients were fully informed of all aspects of the procedure, and all provided written informed consent. Ethics committee approval was obtained.

In each case, the preoperative examination included VA measurements and examination of the anterior segment to identify the entry site, to assess corneal clarity and evaluate any lens injury. In each case, the presence of vitreous hemorrhage precluded the use of fundus photography. B-scan ultrasonography was performed in all cases to locate the exit site, to detect the presence or absence of a retinal detachment or suprachoroidal hematoma and to localize any associated IOFB.

We obtained radiographs and computed tomography (CT) scans of the orbit. Conventional 20-gauge vitrectomy was performed. Before opening the infusion cannula, the entry site was examined to detect any leakage. In four cases, phacoemulsification and intraocular lens (IOL) implantation due to blood staining of the posterior capsule was done at the same time as the vitrectomy.

In all cases, the vitrectomy sought to remove vitreous that had coalesced around the sclerotomy site. This approach was designed to prevent retinal traction and rapid movement. During the procedure, the peripheral vitreous was shaved closely, in order to detect any peripheral breaks (either related to the sclerotomy or preexisting) to trim the vitreous surrounding the exit site and to release any retinal tissue that had coalesced around the exit site. Any hematoma proximal to the exit site was removed with caution, so as not to block the exit site. In some cases, only partial removal was possible.

An endolaser (diode laser) was applied to the area surrounding the exit site and any associated retinal tears. The data collected perioperatively included entrance-site patency, lens clarity, location of the exit site, the presence of an associated IOFB, and the presence of any associated damage, such as a retinal detachment or submacular hemorrhage.

The patients were examined 1 day, 1 week, 1 month, 2 months, 4 months, and 8 months after the surgery. The postoperative examination included VA assessment using logarithm of minimum angle of resolution units and intraocular pressure (IOP) measurements. Any associated complications were recorded.

\section{Results}

In total, 18 patients (18 eyes) with double-perforation gunshot injuries were treated. Five patients had bilateral involvement.
The surgery was performed after repair of the primary scleral wound. This was $<1$ week in one patient (5\%), 2-3 weeks after the primary repair in 13 patients $(73 \%)$, and 3-6 weeks after the primary repair in four patients $(22 \%)$ (Table 1$)$.

\section{Intraoperative results}

\section{Entrance-site closure}

The scleral wound was well closed in 17 eyes. Leakage was observed in only one case that had been operated upon 1 week after the repair. Eleven patients (61\%) exhibited temporal entry, and seven patients (38\%) exhibited nasal entry (Figure 1).

\section{Lens clarity}

The lens was clear in 14 cases $(77 \%)$, while the other four cases $(22 \%)$ exhibited blood staining of the posterior capsule. These cases were treated with phacoemulsification and IOL implantation at the time of surgery.

\section{Exit site}

Exit sites were nasal in one case (5\%) (Figure 2), and between the temporal arcades in three cases (16\%). Postoperative macular dragging developed in this latter group (Figure 3); the exit site was in the inferior periphery in four cases $(22 \%)$, and in the temporal periphery in ten cases (55\%) (Figure 4).

In the case operated upon after 1 week, the exit site had not healed completely. Leakage was observed at the site during the air-fluid exchange. The presence of an associated IOFB was observed in two cases (11\%). Two cases exhibited retinal detachment $(11 \%)$, retinal tissue abnormalities were observed at the exit site in three cases (16\%), and submacular hemorrhage was observed in four cases (22\%) (Table 2).

In all phakic patients, silicone oil removal and cataract removal were performed simultaneously 3-6 months after the vitrectomy. The postoperative follow-up period was

Table I Age and sex distribution of the patient population and time to surgery after primary repair

\begin{tabular}{ll}
\hline Variables & \\
\hline Sex & $16(88 \%)$ \\
Male & $2(11 \%)$ \\
Female & 18 \\
Total number of cases & \\
Age, years & $15-33$ \\
Minimum-maximum & $24 \pm 9$ \\
Mean \pm standard deviation & \\
Duration after primary repair & I patient $(5 \%)$ \\
One week & 13 patients $(73 \%)$ \\
Between 2 and 3 weeks & 4 patients $(22 \%)$ \\
Between 3 and 6 weeks
\end{tabular}




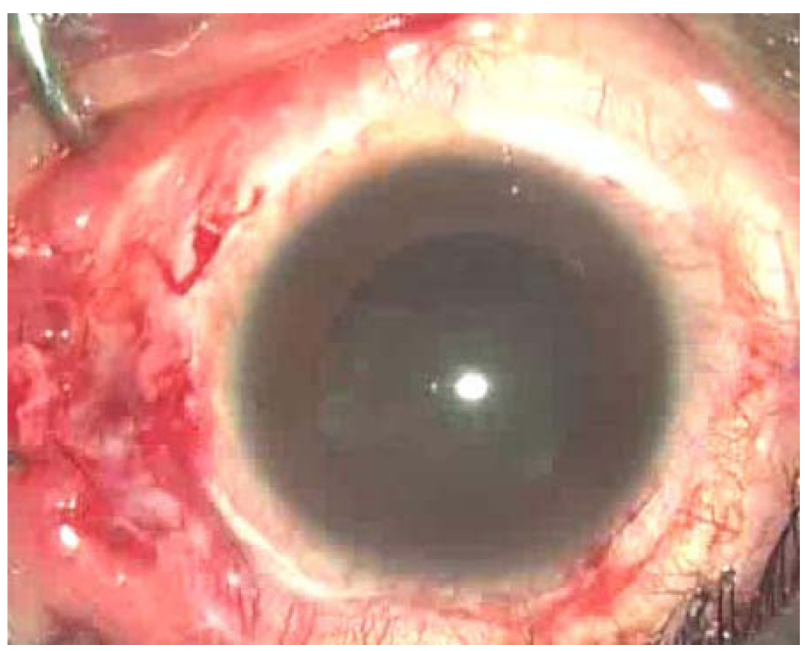

Figure I Intraoperative view, showing a nasal entry site.

$8 \pm 2$ months from the date of this dual procedure. Two eyes (11\%) achieved best-corrected visual acuity (BCVA) of 0.5 , nine eyes $(50 \%)$ achieved BCVA of $0.5-0.1$, and seven eyes (38\%) achieved BCVA between 0.1 and hand movement (HM).

The first two patients described had nasal and inferior peripheral exit sites. Eyes with BCVA between 0.1 and HM exhibited intraoperative submacular hemorrhage and postoperative macular dragging, due to contraction around the exit site. The average postoperative IOP was $19 \mathrm{mmHg}$ (Table 3).

The main reasons for functional failure (VA 0.1-HM) were macular dragging (due to fibrosis at the exit site) in seven cases $(38 \%)$, submacular hemorrhage in four cases (22\%), and epimacular fibrosis in five cases (27\%) (Table 4). All cases developed postoperative exotropia; one case

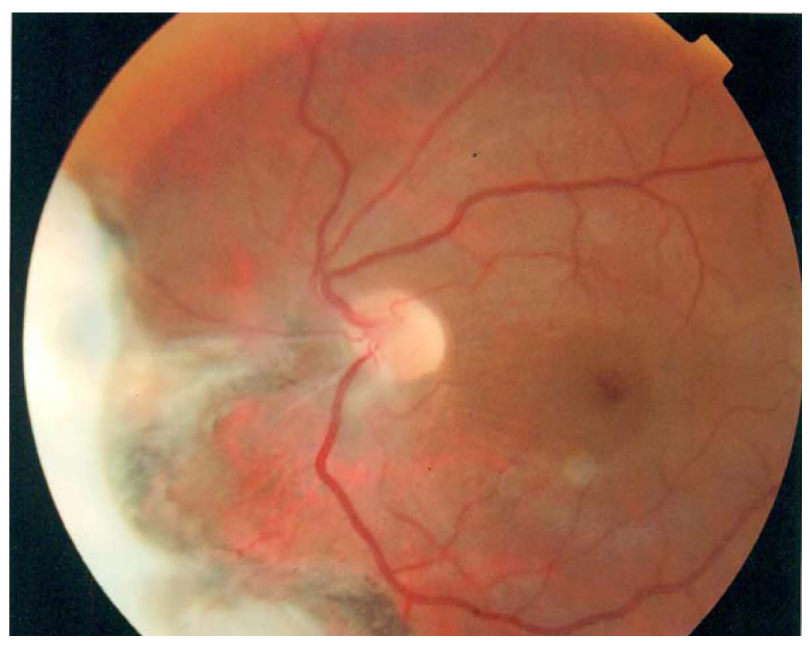

Figure 2 Postoperative view, showing a nasal exit.

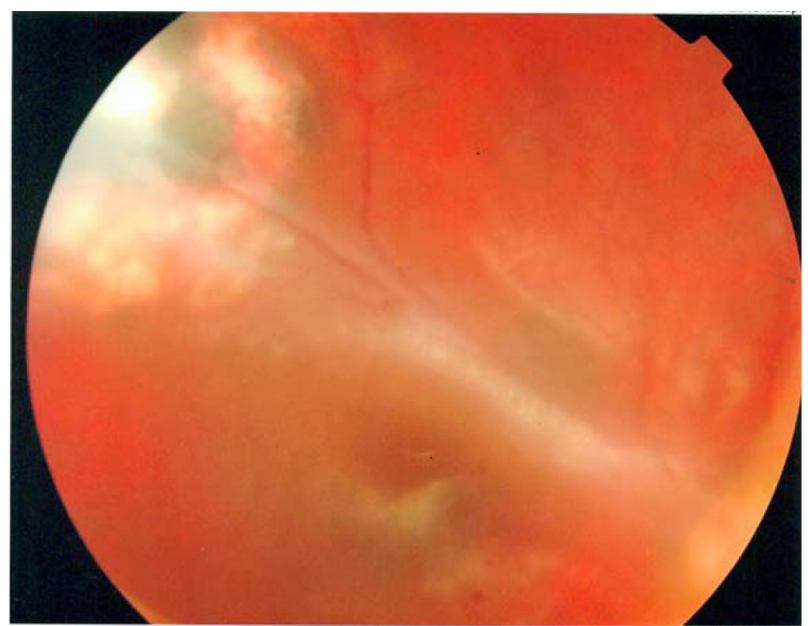

Figure 3 Postoperative view, showing a temporal exit with macular dragging.

$(0.05 \%)$ developed postoperative hemorrhage after removal of the silicone oil. No instance of retinal detachment was reported postoperatively.

\section{Discussion}

The incidence of open-globe injury is about 3.6 to 3.8 per 100,000 around the world. ${ }^{13-15}$ According to the Birmingham Eye Trauma Terminology system, open-globe injury can be classified as laceration or rupture injuries; among laceration injuries, those in which a single foreign body has created the entrance and exit sites are considered a double-penetrating globe. If the entrance wound is not associated with an exit, the injury is defined as a penetrating injury. ${ }^{16}$

The incidence of this type of injury peaks among young adults and elderly individuals aged $>70$ years. Open-globe injuries are much more common among men. This may reflect the more aggressive characteristics of male behavior. ${ }^{14}$ In the

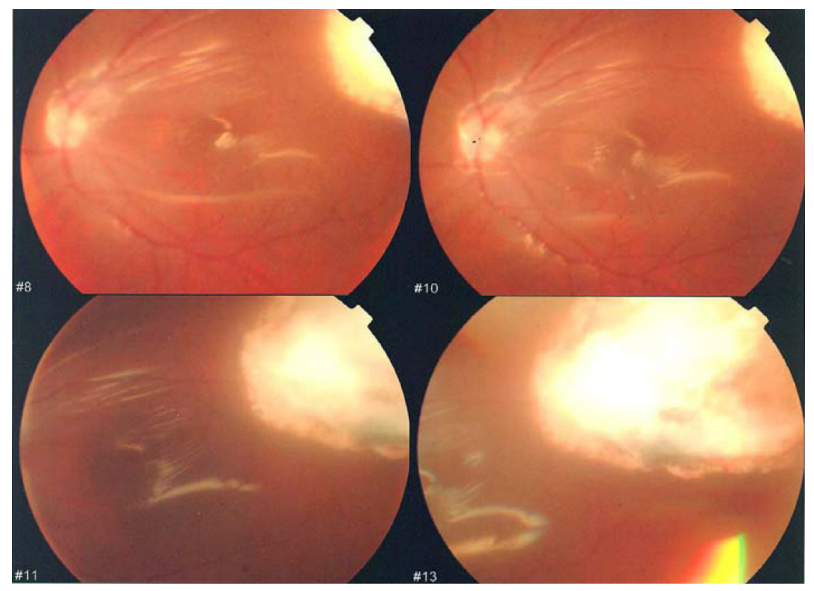

Figure 4 Postoperative view, showing a peripheral exit. 
Table 2 Intraoperative results

\begin{tabular}{lllll}
\hline Inlet patency & Lens clarity & Exit site & IOFB & Associated damage \\
\hline Well closed: I7 (95\%) & Clear in I4 (77\%) & Peripheral lower in 4 cases (22\%) & 2 cases (II\%) & RD in 2 cases (II\%) \\
Leakage: I (5\%) & Opacified in 4 (22\%) & Peripheral temporal in 10 cases (55\%) & & Retinal incarceration in 3 cases (16\%) \\
& & Near the arcades in 3 cases (16\%) & Submacular hemorrhage in 4 cases (22\%) \\
& & Nasal in one case (5\%) & \\
\hline
\end{tabular}

Abbreviations: IOFB, intraocular foreign body; RD, Retinal Detachment.

current study, the mean age was 24 (15-33) years; there were 16 men (88\%) and two women (11\%).

Perforations often occur at the weak points of the globe, such as the limbus and insertion area of the extraocular muscle, and most perforations $(70 \%)$ are located anterior to the ora serrata. ${ }^{17}$ Endophthalmitis occurs in $2 \%-7 \%$ of patients with penetrating injuries. The incidence increases to $7 \%-31 \%$ if the IOFB remains in the eye. ${ }^{17}$

Experimental and clinical studies suggest that among all types of globe wounds, double-perforating injuries have the worst prognosis. ${ }^{18-20}$ Shotgun injuries affecting both sides are also associated with poor visual prognosis. The factors limiting complete or near-complete visual recovery include direct injury to the optic nerve or macula, intraocular scarring and fibrosis with secondary retinal detachment, and severe ocular disorganisation. ${ }^{21,22}$

There are several predictive factors relative to the prognosis for final VA. These include poor presenting BCVA, the presence of a relative afferent pupillary defect, old age, blunt injury with eyeball rupture, a posterior injury site, lid laceration, lens damage, vitreous hemorrhage, and the presence of an IOFB. ${ }^{23,24}$ In all cases, a prompt preoperative evaluation and meticulous vitrectomy will increase the likelihood of a good anatomical and visual outcome.

Among the patients profiled here, the main reasons for functional failure (VA 0.1-HM) were macular dragging (due to fibrosis at the exit site near the macula) in seven cases (38\%), submacular hemorrhage in four cases $(22 \%)$, and epimacular fibrosis in five cases $(27 \%)$.

The standard practice for open-globe injury is to undertake primary surgical repair to restore the structural integrity of the globe, to resolve any hypotonia and to recreate the barrier against infection at the earliest opportunity.

Table 3 Postoperative results

\begin{tabular}{ll}
\hline Postoperative BCVA & Postoperative IOP \\
\hline 0.5 in 2 cases (II\%) & \\
Between 0.5 and 0.1 in 9 cases (50\%) & $9-29 \mathrm{mmHg}$ \\
Between 0.1 and HM in 7 eyes (38\%) & Mean $19 \mathrm{mmHg}$ \\
\hline
\end{tabular}

Abbreviations: BCVA, best-corrected visual acuity; IOP, intraocular pressure; $\mathrm{HM}$, hand movement.
Only when the injury is beyond primary repair is enucleation considered. In the case of a double-penetrating injury, the posterior exit wound is often left to heal spontaneously without surgical intervention. Experimental animal studies have shown that scleral wounds are closed with fibrosis by day 7 after injury.

\section{Plain radiography, ultrasonography examination, and orbital scan}

CT scans can provide enough information to locate an IOFB, to identify any choroidal hemorrhage, and to evaluate ocular integrity. In the current study, all cases underwent vitrectomy 1-6 weeks after entrance-site repair. The surgery was performed $<1$ week after repair of the primary scleral wound in one patient $(5 \%)$, within 2-3 weeks after the primary repair in 13 patients $(73 \%)$, and 3-6 weeks after the primary repair in four patients $(22 \%)$.

The ideal timing of vitrectomy in ocular trauma is still controversial, but early vitrectomy is crucial in the presence of associated retinal detachment and/or endophthalmitis. In the animal model developed by Cleary and Ryan, intraocular blood triggered posterior vitreous detachment 1 week after an artificial penetrating injury. Cell proliferation on the retinal surface and vitreous induced tractional retinal detachment 6 weeks later. On the basis of these results, the authors advised that vitrectomy should be performed $<14$ days after the injury. ${ }^{25}$

For perforating injuries with involvement of the posterior segment, several vitreoretinal surgeons have reported that the vitrectomy should be performed within 2 weeks. Coleman preferred early surgery within 72 hours in order to reduce inflammation by removing any inciting agents in an expedient fashion. ${ }^{11}$ Ryan and Allen believed the optimum time for vitrectomy to be 4-10 days after the original injury in cases with IOFB. ${ }^{26}$ Winthrop et al reported histological findings

Table 4 Causes of functional failure

\begin{tabular}{lll}
\hline $\begin{array}{l}\text { Macular } \\
\text { dragging }\end{array}$ & $\begin{array}{l}\text { Submacular } \\
\text { hemorrhage }\end{array}$ & $\begin{array}{l}\text { Epimacular } \\
\text { fibrosis }\end{array}$ \\
\hline 7 cases $(38 \%)$ & 4 cases $(22 \%)$ & 5 cases $(27 \%)$ \\
\hline
\end{tabular}


for 34 eyes that had severe penetrating trauma; 32 of 34 eyes had retinal detachments. The authors concluded that vitrectomy should not be delayed beyond the second week of injury, by which time massive cellular ingrowth may already be under way. ${ }^{27}$

With regard to the use of silicone oil for most vitrectomies, the superiority of silicone oil over $\mathrm{SF}_{6}$ in cases of retinal detachment with proliferative vitreoretinopathy has previously been established. ${ }^{28}$ An overall reattachment rate of $78.18 \%$ and functional success of $56.36 \%$ has been reported, while those that had proliferative vitreoretinopathy and underwent silicone oil implantation had a reattachment rate of $63.64 \% .{ }^{29}$ Other investigators reported total reattachment caused by trauma in silicone oil-filled eyes in 52\%-62\% of cases..$^{30}$ In the current study, silicone oil 5000 was used in all cases to prevent rebleeding from the exit wound.

In a similar case report on a patient with doubleperforation gunshot injury with a scleral entrance and a nasal exit, the patient's BCVA recovered to 6/12 1 week postoperatively, and 6/8.6 at 20-month follow-up. ${ }^{31}$ In the current study, two eyes (11\%) achieved BCVA of 0.5 , nine eyes (50\%) achieved BCVA of $0.5-0.1$, and seven eyes (38\%) achieved BCVA of 0.1-HM.

In conclusion, the outcome of vitrectomy with silicone oil tamponade in cases of double-perforation gunshot injury depends on various factors performed $<2$ weeks after the primary repair. A meticulous vitrectomy with peripheral shaving to release any retinal traction at the exit site should be performed using a silicone oil tamponade.

\section{Disclosure}

The author reports no conflicts of interest in this work.

\section{References}

1. Rahman I, Maino A, Devadason D, Leatherbarrow B. Open globe injuries: factors predictive of poor outcome. Eye (Lond). 2006;20:1336-1341.

2. Coles WH, Haik GM. Vitrectomy in intraocular trauma. Its rationale and its indications and limitations. Arch Ophthalmol. 1972;87:621-628.

3. Hutton WL, Snyder WB, Vaiser A. Vitrectomy in treatment of ocular perforating injuries. Am J Ophthalmol. 1976;81:733-779.

4. Cleary PE, Ryan SJ. Experimental posterior penetrating eye injuries in the rabbit. I. Method of production and natural history. Br J Ophthalmol. 1979;63:306-311.

5. Topping TM, Abrams GW, Machemer R. Experimental double-perforating injury of the posterior segment in rabbit eyes: the natural history of intraocular proliferation. Arch Ophthalmol. 1979;97:735-742.

6. Gregor Z, Ryan SJ. Complete and core vitrectomies in the treatment of experimental posterior penetrating eye injury in the rhesus monkey. II. Histologic features. Arch Ophthalmol. 1983;101:446-450.

7. Hsu HT, Ryan SJ. Experimental retinal detachment in the rabbit. Penetrating ocular injury with retinal laceration. Retina. 1986;6:66-69.

8. Benson WE, Machemer R. Severe perforating injuries treated with pars plana vitrectomy. Am J Ophthalmol. 1976;81:728-732.
9. Conway BP, Michels RG. Vitrectomy techniques in the management of selected penetrating ocular injuries. Ophthalmology. 1978;85: 560-583.

10. Michels RG. Vitrectomy methods in penetrating ocular trauma. Ophthalmology. 1980;87:629-645.

11. Coleman DJ. Early vitrectomy in the management of the severely traumatized eye. Am J Ophthalmol. 1982;93:543-551.

12. Meredith TA, Gordon PA. Pars plana vitrectomy for severe penetrating injury with posterior segment involvement. Am J Ophthalmol. 1987;103: 549-554.

13. Fong LP. Eye injuries in Victoria, Australia. Med J Aust. 1995;162: 64-68.

14. Wong TY, Tielsch JM. A population-based study on the incidence of severe ocular trauma in Singapore. Am J Ophthalmol. 1999;128: $345-351$.

15. Gilbert CM, Soong HK, Hirst LW. A two-year prospective study of penetrating ocular trauma at the Wilmer ophthalmological institute. Ann Ophthalmol. 1987;19:104-106.

16. Kuhn F, Morris F, Witherspoon CD, Mester V. The Birmingham Eye Trauma Terminology system (BETT). J Fr Ophthalmol. 2004;27: 206-210.

17. Wirostko WJ, William FM, McCabe CM, Dieckert JP. Intraocular foreign bodies. In: Albert DM, Jakobiec FA, editors. Principles and Practice of Ophthalmology. 2nd ed. Philadelphia: Saunders; 2000: 5241-5250.

18. Abrams GW, Topping TM, Machemer R. Vitrectomy for injury: the effect on intraocular proliferation following perforation of the posterior segment of the rabbit eye. Arch Ophthalmol. 1979;97:743-748.

19. De Juan E Jr, Sternberg P Jr, Michels RG, Auer C. Evaluation of vitrectomy in penetrating ocular trauma. A case-control study. Arch Ophthalmol. 1984;102:1160-1163.

20. Ramsay RC, Cantrill HL, Knobloch WH. Vitrectomy for double penetrating ocular injuries. Am J Ophthalmol. 1985;100:586-589.

21. Morris RE, Witherspoon CD, Feist RM, Byme JB Jr, Ottemiller DB. Bilateral ocular shotgun injury. Am J Ophthalmol. 1987;103: 695-700.

22. Sternberg P Jr, de Juan E Jr, Green WR, Hirst LW, Sommer A. Ocular BB injuries. Ophthalmology. 1984;91:1269-1277.

23. Hatton MP, Thakkar MM, Ray S. Orbital and adnexal trauma associated with open globe injuries. Ophthal Plast Reconstr Surg. 2002;18:458-461.

24. Schmidt GW, Broman AT, Hindman HB, Grant MP. Vision survival after open globe injury predicted by classification and regression tree analysis. Ophthalmology. 2008;115:202-209.

25. Cleary PE, Ryan SJ. Method of production and natural history of experimental posterior penetrating eye injury in the monkey. Am J Ophthalmol. 1979;88:212-220.

26. Ryan SJ, Allen AW. Pars plana vitrectomy in ocular trauma. Am J Ophthalmol. 1979;88:483-491.

27. Winthrop SR, Cleary PE, Minckler DS, Ryan SJ. Penetrating eye injuries: a histopathological review. Br J Ophthalmol. 1980;64:809-817.

28. [No authors listed]. Vitrectomy with silicone oil or sulfur hexafluoride gas in eyes with severe proliferative vitreoretinopathy: results of a randomized clinical trial. Silicone Study Report 1. Arch Ophthalmol. 1992;110:770-779.

29. Warrasak S, Euswas A, Hongsakorn S. Posterior segment trauma: types of injuries, result of vitreo-retinal surgery and prophylactic broad encircling scleral buckle. J Med Assoc Thai. 2005;88:1916-1930.

30. Skorpik C, Menapace R, Gnad H, Parousis P. Silicone oil implantation in penetrating ocular injuries complicated by PVR. Result from 1982 to 1986. Retina. 1989;9:8-14.

31. Hung KH, Yang CS, Kao SC, Lee FL, Lee SM. Management of doublepenetrating ocular injury with retained intraorbital metallic foreign body. J Chin Med Assoc. 2011;74:523-526. 


\section{Publish your work in this journal}

Clinical Ophthalmology is an international, peer-reviewed journal covering all subspecialties within ophthalmology. Key topics include: Optometry; Visual science; Pharmacology and drug therapy in eye diseases; Basic Sciences; Primary and Secondary eye care; Patient Safety and Quality of Care Improvements. This journal is indexed on
PubMed Central and CAS, and is the official journal of The Society of Clinical Ophthalmology (SCO). The manuscript management system is completely online and includes a very quick and fair peer-review system, which is all easy to use. Visit http://www.dovepress.com/ testimonials.php to read real quotes from published authors. 